Subscriber access provided by University of Otago Library

\title{
Article
}

\section{Demulsification of Crude Oil-in-Water Emulsions Driven by Graphene Oxide Nanosheets}

\author{
Juan Liu, Xiaocheng Li, Weihong Jia, Zhiyun Li, Yapu Zhao, and Sili Ren
}

Energy Fuels, Just Accepted Manuscript • DOI: 10.1021/acs.energyfuels.5b00966 • Publication Date (Web): 24 Jun 2015

Downloaded from http://pubs.acs.org on July 2, 2015

\section{Just Accepted}

"Just Accepted" manuscripts have been peer-reviewed and accepted for publication. They are posted online prior to technical editing, formatting for publication and author proofing. The American Chemical Society provides "Just Accepted" as a free service to the research community to expedite the dissemination of scientific material as soon as possible after acceptance. "Just Accepted" manuscripts appear in full in PDF format accompanied by an HTML abstract. "Just Accepted" manuscripts have been fully peer reviewed, but should not be considered the official version of record. They are accessible to all readers and citable by the Digital Object Identifier (DOI®). "Just Accepted" is an optional service offered to authors. Therefore, the "Just Accepted" Web site may not include all articles that will be published in the journal. After a manuscript is technically edited and formatted, it will be removed from the "Just Accepted" Web site and published as an ASAP article. Note that technical editing may introduce minor changes to the manuscript text and/or graphics which could affect content, and all legal disclaimers and ethical guidelines that apply to the journal pertain. ACS cannot be held responsible for errors or consequences arising from the use of information contained in these "Just Accepted" manuscripts. 


\title{
Demulsification of Crude Oil-in-Water Emulsions Driven by Graphene Oxide Nanosheets
}

\author{
Juan Liu, ${ }^{\dagger, \star}$ Xiaocheng Li, ${ }^{£}$ Weihong Jia, ${ }^{\dagger}$ Zhiyun Li, ${ }^{\dagger, \star}$ Yapu Zhao, ${ }^{\S}$ Sili Ren ${ }^{*}{ }^{\dagger}$ \\ ${ }^{\dagger}$ State Key Laboratory of Solid Lubrication, Lanzhou Institute of Chemical Physics, \\ Chinese Academy of Sciences, Lanzhou 730000, People's Republic China \\ ${ }^{\ddagger}$ University of Chinese Academy of Sciences, Beijing 100049, People’s Republic \\ China \\ ${ }^{£}$ Laboratory of Clean Energy Chemistry and Materials, Lanzhou Institute of Chemical \\ Physics, Chinese Academy of Sciences, Lanzhou 730000, People's Republic China \\ ${ }^{\S}$ State Key Laboratory of Nonlinear Mechanics, Institute of Mechanics, Chinese \\ Academy of Sciences, Beijing 100190, People's Republic China
}

\begin{abstract}
Seeking highly-efficient, rapid, universal and low-cost demulsification materials to break up the crude/heavy oil-in-water emulsion and emulsified oily wastewater at ambient condition has been the goal of petroleum industry. In this work, an amphiphilic material, graphene oxide nanosheets (GO), was introduced as a versatile demulsifier to break up the oil-in-water emulsion at room temperature. It was encouraging to find that the small oil droplets in the emulsion quickly coalesced to form the oil phase and separated with the water within a few minutes. The demulsification tests indicated that the residual oil in separated water samples were as low as $\sim 30 \mathrm{mg} / \mathrm{L}$ corresponding to a demulsification efficiency over $99.9 \%$ at an optimum GO dosage. More importantly, GO is not only useful for ordinary crude oil emulsion, but also can be used to break up the extra heavy oil emulsion. Effect of the
\end{abstract}


emulsion $\mathrm{pH}$ on the demulsification was also investigated. It was interesting to find that the distribution of GO either in oil or in water phase after demulsification was dependent on the $\mathrm{pH}$ value of the solution, which was attributed to the $\mathrm{pH}$-dependent amphiphilicity of GO. The prominent demulsification ability of GO was attributed to the strong adsorption between the GO nanosheets and molecules of asphaltenes/resins driven by $\pi-\pi$ interaction and/or $n-\pi$ interaction. The findings in this work indicate that the GO nanosheets is a simple, high-efficient and universal demulsifier to separate the oil from the crude/heavy oil-in-water emulsions at ambient condition, which shows a good application prospect in oil industry.

\section{Introduction}

Demulsification of crude/heavy oil-water emulsion (including oil/water and water/oil emulsions) is a major issue that received sustained attention for decades in the petroleum industry. ${ }^{1,2}$ At the early stage, researchers mainly focused on the demulsification of water-in-oil emulsions due to the exploitation of primarily developed oilfield in which less water was contained. As an economical and effective method, chemical additives are widely used to break up the water-in-oil (W/O) emulsion. In practice, amphiphilic surfactants such as ethylene glycol, ${ }^{3}$ ethylene oxide/propylene oxide copolymer, ${ }^{4-7}$ silicone surfactant, ${ }^{8}$ ethyl cellulose, ${ }^{9,}, 10$ ion liquid $^{11,12}$ and $\mathrm{P}(\mathrm{MMA}-\mathrm{AA}-\mathrm{DVB}) / \mathrm{Fe}_{3} \mathrm{O}_{4}$ Janus particles ${ }^{13}$ etc. have been developed to separate water from W/O emulsion. However, with the excessive exploitation of traditional fossil fuel, study on oil-in-water $(\mathrm{O} / \mathrm{W})$ emulsion has aroused great attention. With the gradual ageing of oil field, innovative techniques and approaches 
such as tertiary oil recovery technique were widely used to increase the output in China and other countries. The introductions of steam, water and the extraction auxiliary agents to oil reservoir produce large amount of stable crude $\mathrm{O} / \mathrm{W}$ emulsion. In recent years, much attention was focused on the exploitation of non-conventional heavy oil and extraction of bitumen from oil sands. ${ }^{14-18}$ However, the high viscosities of heavy crude oil make it difficult to explore and transport due to its low mobility at ambient conditions. The technology of emulsified heavy crude oil was thereby developed, which has proved to be a reliable approach to increase its mobility and reduce the heavy crude oil's viscosity to facilitate the transportation. ${ }^{19}$ To extract bitumen from the oil sands, large amount of water are necessarily used during the water-based extraction processes,${ }^{20,21}$ which produce a large amount of emulsified oily wastewater. Moreover, mass of the oily wastewater was also produced from the conventional oilfield exploitation and industrial refinery. ${ }^{22}$ All the oily wastewater brought up serious environmental issues, which need to be efficiently treated before discharge. Therefore, treatment of various $\mathrm{O} / \mathrm{W}$ emulsions has become one of the most serious challenges in petroleum industries. It is necessary to develop a fast and high efficiency method to separate the oil from $\mathrm{O} / \mathrm{W}$ emulsions.

Many strategies including the gravity separation, coalescence technology, ${ }^{23}$ filtration/membrane separation, ${ }^{24-26}$ absorption, ${ }^{27}$ air flotation, ${ }^{28}$ coagulation sedimentation, ${ }^{29}$ electrolysis process, ${ }^{30}$ ultrasonic treatment, ${ }^{31,} 32$ and biological treatment $^{33,34}$ etc. have been widely adopted to separate the oil from the $\mathrm{O} / \mathrm{W}$ emulsions. However, most of the separation technologies are high costly, 
energy-intensive, complex, and time-consuming. Graphene oxide sheets, normally referred as graphene oxide (GO), are the liquid phase oxidation-exfoliation product of graphite. In form of graphene sponge and mesh, ${ }^{35-39}$ graphene is often used to absorb or filter oil based on its low surface energy, low density and high surface area. ${ }^{40}$ In fact, introduction of the functional groups of carbonyl, hydroxyl and ethyoxyl on the edges of GO enables it a good amphipathic surfactant with hydrophilic edges and hydrophobic basal plane. ${ }^{41-44}$ Therefore, the functionalized GO might find it important application in demulsification of the $\mathrm{O} / \mathrm{W}$ emulsion. In this work, GO was reported as an excellent demulsifier to quickly separate the oil from $\mathrm{O} / \mathrm{W}$ emulsion within a few minutes. Bottle test and optical observation were employed to evaluate the demulsification performance of GO. Operating condition was investigated and optimized by studying effect of the GO dosage and solution $\mathrm{pH}$ on the demulsification. The possible mechanism on demulsification process was proposed. As an environmental friendly and high efficient demulsifier, GO might find its application in separating oil from the $\mathrm{O} / \mathrm{W}$ emulsion in the petroleum industry.

\section{Experimental Section}

2.1 Materials. All chemical reagents were analytical grade purity and directly used without further treatment. The medium/heavy crude oil samples were provided by Tahe oilfield (Xingjiang province, China) and Shengli oilfield (Shangdong province, China), respectively. The physicochemical properties of two crude oil samples were characterized and listed in Table 1. The SARA fraction (saturates, aromatics, resins and asphaltenes) of these two crude oil were analyzed by a classical 
chromatography separation method. ${ }^{18}$ The total percentage of SARA in crude oil were less than $100 \%$ in these analyses, indicated that some fraction was left in the chromatographic column. The kerosene was obtained from local gas station of Sinopec (Lanzhou, China). De-ionized water $(18.25 \mathrm{M} \Omega \cdot \mathrm{cm})$ was used throughout all experiment process.

2.2 Preparation of Graphene Oxide Nanosheets. Graphite powder $(\sim 20 \mu \mathrm{m}$, Sigma-Aldrich) was used to prepare the graphene oxide by a modified Hummers' method (The detail of preparation of GO are provided in supporting information (S1)). ${ }^{45,46}$ Exfoliation was carried out by ultrasonic of $2 \mathrm{mg} / \mathrm{mL}$ GO dispersion for more than 90 min under ambient condition.

Fourier transform infrared spectroscopy (FTIR, Nexus 870) and Raman spectroscopy (Renishaw in Via-Reflex) were used to characterize the surface chemical state of the as-prepared GO nanosheets. The thickness and size of the GO material was determined by using atomic force microscopy (AFM, Bruker Multimode-8) with tapping mode operating at a scan rate of $2 \mathrm{~Hz}$. The surface morphology was characterized with a high resolution transmission electron microscope (HRTEM, FEI Tecnai G2 TF20). The HRTEM samples were prepared by dipping the GO suspension onto a porous polymer coated copper grid.

2.3 Preparation of Crude Oil-in-Water Emulsion. The crude oil obtained from Tahe oil field was directly used without further treatment. The heavy crude oil obtained from Shengli oil field was kept at $60^{\circ} \mathrm{C}$ for $1 \mathrm{~h}$ to make the oil much more mobile and readily dispersed. Crude oil samples (dispersed phase) were mixed with 
$50 \mathrm{mM} \mathrm{NaCl}$ solution (continuous phase) using a homogenizer (Fluko, FA25) running at $28000 \mathrm{rpm}$ for $5 \mathrm{~min}$ to simulate the real condition of oil field. A stable oil-in-water emulsion was thereby obtained with different oil content. In this work, crude oil-in-water emulsion or emulsified oily wastewater with the oil content of $100 \mathrm{~g} / \mathrm{L}$, $50 \mathrm{~g} / \mathrm{L}, 5 \mathrm{~g} / \mathrm{L}$ and $1 \mathrm{~g} / \mathrm{L}$ were employed.

2.4 Demulsification Test. To evaluate the demulsification capability, the GO suspension $(2 \mathrm{mg} / \mathrm{mL})$ was added to $40 \mathrm{~mL}$ of crude oil-in-water emulsion contained in a capped cylinder (The dosage of GO in the demulsification can be calculated based on the mass concentration of GO in emulsion. For example, if $0.4 \mathrm{~mL} \mathrm{GO}$ was added, the dosage of GO in the emulsion was $20 \mathrm{mg} / \mathrm{L}$.), and then the cylinders were shaken for 2 min to make the GO and the emulsion to be well mixed. The mixture was then placed under ambient condition to observe the oil/water separation. The cylinders containing oil-in-water emulsion with same volume of water or $\mathrm{HCl}$ solution $(0.05 \mathrm{M})$ were employed as references (blank).

The prepared emulsion and the GO-driven demulsification processes were observed and photographed using a microscope (Leica, DM2500P) equipped with a video camera. The emulsion samples were placed on a cleaned glass slide $(25 \times 75 \times 0.2$ $\mathrm{mm})$ and covered with another slide.

The residual oil content in the separated water samples were determined based on absorbance in UV-visible spectrophotometer (Unico, UV-2000) at 1cm path length. Take kerosene as reference, the relationship of absorbance and kerosene-diluted-oil concentration is linear at the wavelength of $350 \mathrm{~nm}$. Specifically, the crude 
oil-in-water emulsion was treated by GO suspension in different concentration and then gravity settle for $30 \mathrm{~min}$, and the separated water samples were collected from each separation bottle carefully. Successively, the oil in the separated water samples were extracted and diluted by kerosene. The concentration of oil can be obtained from the standard curve. The oil concentration in separated water samples were calculated by following equation:

$$
c_{o}=m_{o} / V_{w} \times 10^{3}
$$

Where the $c_{o}(\mathrm{mg} / \mathrm{L})$ is the oil concentration, $m_{o}(\mathrm{mg})$ is the corresponding mass of oil in the standard curve and $V_{w}(\mathrm{~mL})$ is the water volume. The demulsification efficiency was calculated from the difference between the initial and final oil content in the mixture by following equation:

$$
E=\left(c_{0}-c_{i}\right) / c_{0} \times 100 \%
$$

Where $E$ is the demulsification efficiency $(\%), c_{0}$ is the initial oil content $(\mathrm{mg} / \mathrm{L})$ of emulsion and $c_{i}$ is the residual oil content in the separated water.

The UV-Vis absorption spectrophotometer (Pgeneral, T6) was used to study the GO distribution after demulsification at various conditions.

Zeta potential of the GO nanosheets and crude oil (Tahe) were measured with a zeta potential analyzer (Brookhaven, ZetaPALS). The GO and crude oil were dispersed in $1 \mathrm{mM} \mathrm{KCl}$ solution by ultrasonic for at least $90 \mathrm{~min}$, respectively. The as-prepared suspension was adjusted to desired $\mathrm{pH}$ by adding diluted $\mathrm{HCl}$ or $\mathrm{NaOH}$. The measurement was repeated ten times at room temperature $\left(25 \pm 1{ }^{\circ} \mathrm{C}\right)$. The average value and standard deviation are reported. 


\section{Results and Discussion}

3.1 Characterizations of the GO Nanosheets. Figure 1a shows the FTIR spectrum of the GO sample. It was found that several characteristic peaks appeared in the range of $800-4000 \mathrm{~cm}^{-1}$. Specifically, a characteristic broad peaks centered at 3424 $\mathrm{cm}^{-1}$ was assigned to hydroxyl groups (-OH) and peaks located at $2962 \mathrm{~cm}^{-1}$ and 2923 $\mathrm{cm}^{-1}$ were the stretching vibration of $\mathrm{C}-\mathrm{H}\left(-\mathrm{CH}_{2}\right)$. The carbonyl $(-\mathrm{C}=\mathrm{O})$ peak assigned to carboxyl groups $(-\mathrm{COOH})$ appears at $1720 \mathrm{~cm}^{-1}$. Stretching vibration peaks located at $1266 \mathrm{~cm}^{-1}$ and $1050 \mathrm{~cm}^{-1}$ were assigned to the alkoxy groups (O-C-O). These findings suggested that functional groups of alkoxyl, carbonyl and hydroxyl were successfully introduced on the graphene surface after being oxidized by the strong oxidants. ${ }^{47}$ Considering the advantages of Raman spectroscopy in determining surface chemical state and crystallinity of carbon materials, it was also employed to characterize the as-prepared GO sample. As shown in Figure 1b, Raman spectrum of pristine graphite powder displayed as a visible D band at $1350 \mathrm{~cm}^{-1}$, a pronounced $\mathrm{G}$ band at $1580 \mathrm{~cm}^{-1}$ and a evident 2D band (second-order feature of $\mathrm{D}$ band) at 2700 $\mathrm{cm}^{-1}$. Comparing with Raman spectrum of graphite powder, it was observed that both $\mathrm{D}$ and $\mathrm{G}$ bands of the GO sample were clearly broadening. Meanwhile, the intensity of the D band increases substantially, indicating the decrease in size of the in-plane $\mathrm{sp}^{2}$ domains and the increase of the $\mathrm{sp}^{3}$-carbon on GO surface due to the extensive oxidation and ultrasonic exfoliation. The typical feature of 2D band of graphite at $2720 \mathrm{~cm}^{-1}$, which contains the detailed information of the stacking number of the graphene sheets, is not seen in GO sample, and only a faint smeared 2D band can be 
seen along with the $\mathrm{D}+\mathrm{G}$ combination band induced by disorder at $2900 \mathrm{~cm}^{-1}$. Combined with Raman spectrum and FTIR spectrum, it can conclude that the graphite was fully functionalized and GO material was obtained. The morphology of the GO was characterized by using AFM and TEM. Figure 1c shows the typical AFM image of the exfoliated GO sample on silicon substrate. It can be observed that the GO nanosheets with size of 40-500 $\mathrm{nm}$ and thickness of $\sim 1.4 \mathrm{~nm}$ are uniformly distributed on silicon surface, implying that the as-prepared GO samples consist of mono/bilayers nanosheets. The TEM image of GO nanosheets was shown in Figure 1d. Wrinkles and defects were observed on surfaces of the GO nanosheets.

3.2 Demulsification Performance of GO Nanosheets. Bottle test is the simple and intuitive method to evaluate the demulsification effectiveness of a demulsifier for crude oil-water emulsion. Figure 2 shows the demulsification process driven by the GO nanosheets. To clear display the demulsification performance, two control oil-in-water emulsion samples (Tahe, $50 \mathrm{~g} / \mathrm{L}$ ) were used as references. As shown in Figure $2 \mathrm{a} 1$ and $2 \mathrm{a} 2$, after adding water or $\mathrm{HCl}$ solution to the crude oil-in-water emulsion, there was no obvious phase separation can be observed even after one day. Encouragingly, after introducing small amount of the GO nanosheets suspension, the stability of emulsion was destroyed instantaneously and oil/water separation process was greatly speeded up (Figure 2a3). Figure $2 \mathrm{~b}$ and video S2 show the details of the oil/water separation process. As noted in Figure 2b, once the GO naonsheets suspension was introduced, the color of emulsion changed immediately from dark brown to black, implying the coalescence of fine oil droplets occurred at that moment. 
After only 8 seconds, macroscopic oil droplets began to form and distinct oil/water interface can be easily observed, suggesting the occurrence of oil/water separation. With following tens of seconds, the oil droplets or floccules were continuously coalesced with each other and floated up to form the oil phase. As the time was prolonged to 115 seconds, the oil was completely separated from emulsion. Accordingly, the condensed oil phase and colorless water phase were clearly observed, indicating a simple, fast and high efficient demulsification process.

To have a deep understanding on the demulsificaition process of the crude oil-in-water emulsion driven by the GO nanosheets, the morphologies of the oil-water mixture at different stage were observed with a polarizing microscope. Figure 3a shows the optical morphology of the as-prepared crude oil-in-water emulsion (Tahe, $50 \mathrm{~g} / \mathrm{L}$ ) dripped on a glass slide surface. As observed, the oil droplets (diameter $<10$ $\mu \mathrm{m})$ homogeneously dispersed in the water phase, which was in good agreement with that the previous study. ${ }^{48}$ As the GO nanosheets suspension was introduced into the emulsion, many irregular oil floccules with much bigger size than that in the original emulsion were observed in the water phase (Figure 3b). Such finding indicates that the GO nanosheets could well interact with the fine oil droplets in the emulsion once they contacted each other, leading to the obvious color changes of the emulsion at the instant addition of the GO suspension. Obviously, the GO nanosheets promoted the coalescence of the fine oil droplets in the emulsion to form the big oil droplets. After thoroughly shaking, the oil floccules aggregated rapidly to form the suspended oil phase floating on the water surface. Figure $3 c$ shows the optical image of the newly 
produced oil phase. It can be seen that some water droplets were wrapped in the oil phase (Figure 3c) due to the rapid coalescence of the oil droplets driven by the GO nanosheets. Fortunately, the water droplets trapped in oil phase could spontaneously coalesced and precipitated at the bottom of vial after being settled by gravity at $60{ }^{\circ} \mathrm{C}$ for $2 \mathrm{~h}$. As shown in Figure 3d, only a few small water droplets still stay in the oil (Figure 3d). Quantitative measurement by Karl Fischer titrator demonstrated that the water content in oil phase after settling was $\sim 0.86 \mathrm{wt} \%$, which approximately approaches the industrial demand for oil refining.

3.3 Effect of GO Dosage on Demulsification. To explore the application field and dosage of GO nanosheets as demulsifier, two kinds of crude oil (Tahe medium oil and Shenli heavy oil) emulsion with different oil content were used to validate its demulsification performance. The demulsification efficiency of the GO nanosheets was evaluated by using a UV-Spectrophotometer to determine the oil content in the separated water. It was found that the GO nanosheets could well demulsify both the emulsions (Figures 4-5). The results indicated that the optimum dosage of the GO noansheets and the demulsification efficiency are closely related to the emulsion type and the oil content of emulsion. As shown in Figure 4, the oil content in the Tahe oil emulsion greatly reduced with addition of the GO nanosheets suspension. A lowest oil content corresponding to a maximum demulsification efficiency was attained at an optimal GO dosage. When the dosage of the GO nanosheets exceeds a threshold, the oil content in the separated water was rather slightly increased. Such an abnormal phenomenon is possibly attributed to the distribution of GO nanosheets after 
demulsification. As the excess GO distributed in water phase, the adsorbed oil on the GO surfaces led to the slight increase of oil content in the separated water samples. Taking the oil emulsion with an initial oil content of $50 \mathrm{~g} / \mathrm{L}$ as an example, the oil content in the separated water greatly reduced to $\sim 315 \mathrm{mg} / \mathrm{L}$ and the demulsification efficiency reached up to $\sim 99.37 \%$ as the GO nanosheets suspension with dosage of 10 $\mathrm{mg} / \mathrm{L}$ was added into the emulsion. Further increasing the GO dosage to about 30 $\mathrm{mg} / \mathrm{L}$, the oil content in the separated water was notably reduced to $\sim 30 \mathrm{mg} / \mathrm{L}$. Correspondingly, the demulsification efficiency reached as high as $99.94 \%$, suggesting that the GO nanosheets, as a demulsifier, possessed high demulsification efficiency and only need a low dosage. While the dosage of GO increased to $80 \mathrm{mg} / \mathrm{L}$, the corresponding demulsification efficiency slightly decreased to $99.89 \%$. For emulsion with oil content of $100 \mathrm{~g} / \mathrm{L}$, similar oil/water separation result was achieved. The optimum dosage of GO nanosheets was $\sim 60 \mathrm{mg} / \mathrm{L}$, slightly higher than that of 50 g/L. Importantly, the optimum dosage of GO naonsheets for emulsion with oil content of $5 \mathrm{~g} / \mathrm{L}$ and $1 \mathrm{~g} / \mathrm{L}$ is as low as $\sim 13 \mathrm{mg} / \mathrm{L}$ and $\sim 7 \mathrm{mg} / \mathrm{L}$, respectively. Moreover, the demulsification process could be finished within 2 minutes.

As a high performance demulsifier, GO nanosheets are also suitable to demulsify the heavy oil/water emulsions. As shown in Figure 5, the optimum dosage of GO nanosheets was $30 \mathrm{mg} / \mathrm{L}$ and $60 \mathrm{mg} / \mathrm{L}$ for Shengli heavy oil/water emulsion with oil content of $50 \mathrm{~g} / \mathrm{L}$ and $100 \mathrm{~g} / \mathrm{L}$, respectively. The corresponding demulsification efficiency reached as high as $99.95 \%$ and $99.94 \%$, respectively. All these results suggest that the GO nanosheets can be used as a fast and high performance 
demulsifier to separate the medium crude oil-in-water emulsion and heavy oil-in-water emulsion, presenting the nature of universality.

3.4 Effect of pH on Demulsification. With the hydrophilic edges and hydrophobic basal plane, GO could be regarded as an amphiphile or a surfactant. It is well known that most of ionic surfactants were apt to be affected by the $\mathrm{pH}$ of solution. We are interested in the applicable conditions of the GO nanosheets as a demulsifier. Therefore, the effect of $\mathrm{pH}$ value of emulsion on demulsification driven by GO was investigated. It was observed that the GO was effective in acid or neutral condition. To have a quantitative analysis, the residual oil content in the separated water at different $\mathrm{pH}$ value as a function of GO nanosheets dosage were measured and depicted in Figure 6a. It was found that the lowest oil content in separated water samples were about $30 \mathrm{mg} / \mathrm{L}$ and varied very little in the $\mathrm{pH}$ range of 2-5.7, implying that as a demulsifier, the GO possessed high stability and excellent demulsification capability in a wide range $\mathrm{pH}$ condition. However, it was noted that there was a slight increase of the GO dosage for a best demulsification efficiency with decreasing the solution $\mathrm{pH}$. For the Tahe emulsion with the oil content of $50 \mathrm{~g} / \mathrm{L}$, the optimum dosage of GO nanosheets concentration was about $20 \mathrm{mg} / \mathrm{mL}$ when the $\mathrm{pH}$ of emulsion was about 5.7. As it decreased to $\sim 3.5$, the optimum dosage was increased to $\sim 40 \mathrm{mg} / \mathrm{mL}$. These findings indicated that the GO nanosheets are also effective of demulsifying the acid oil-in-water emulsion during the well washing process. 
Effect of $\mathrm{pH}$ on the demulsification efficiency in the alkaline solution was also studied. However, it was found that the oil-water separation efficiency was not good especially for a strong alkaline condition such as 10 (The experimental results are not presented). To clarify the $\mathrm{pH}$ effect, the zeta potential of the Tahe crude oil and the GO nanosheets was characterized and the results are shown in Figure 6b. It was shown that the zeta potential for both the oil and GO become more negative with the decrease of $\mathrm{pH}$ value. As a result, the electrostatic repulsion between GO nanosheets and oil droplets would be dramatically increased when they were in a strong alkaline condition, leading to the demulsification efficiency significantly reduced. The results indicate that the $\mathrm{pH}$ value of emulsion should be well considered in the practice of demulsification.

During the demulsification test, it was noticed that the color of the separated water was different even if the residual oil content in the water was same. As shown in Figure $7 \mathrm{a}$, the separated water derived from the demulsification at $\mathrm{pH}=2$ was nearly colorless, while they were yellow for the separated water at $\mathrm{pH}=5.7$ and the control sample (The control water sample was obtained by adding same dosage of GO suspension in brine water). It is believed that the yellow color of the water was originated from either the residual oil or the GO nanosheets. Since the residual oil content in the separated water was nearly the same for the two situations of $\mathrm{pH} 2$ and 5.7, it was concluded that the color of separated water should be affected by the GO nanosheets rather than the residual crude oil. To validate the hypothesis, the control water sample containing GO nanosheets and the two separated water samples were 
extracted by toluene three times to eliminate the oil from the water. The resultant water samples were shown in Figure 7b. It was observed that the color of the control sample and the separated water at pH 5.7 did not change obviously, while the water samples at $\mathrm{pH} 2$ became clearer and colourless. Such finding suggests that the yellow color of the separated water arises from the GO nanosheets dispersed in the water. In order to obtain a direct evidence, the water samples after toluene extraction were characterized by an UV-Vis absorption spectrophotometer. It is well known that the UV-Vis absorption spectrum of GO has two characteristic features which are used as means of identification, i.e. a maximum at $231 \mathrm{~nm}$ corresponding to $\pi \rightarrow \pi^{*}$ transitions of aromatic $\mathrm{C}=\mathrm{C}$ bonds, and a shoulder at $\sim 300 \mathrm{~nm}$ attributing to $\mathrm{n} \rightarrow \pi^{*}$ transitions of $\mathrm{C}=\mathrm{O}$ bonds. ${ }^{49}$ As shown in Figure $7 \mathrm{c}$, both the water sample obtained at $\mathrm{pH}=5.7$ (black) and the control (light green) have the absorption peaks at $\sim 230 \mathrm{~nm}$ and shoulder at $300 \mathrm{~nm}$. While there was no obvious characteristic absorption for water sample obtained at $\mathrm{pH}=2$ (blue). Such finding confirmed that the yellow color comes from the GO nanosheets. In other words, the GO nanosheets preferred to stay in the separated water phase after demulsification at the neutral condition, while they would rather enter in the oil phase under acid condition. It is further interesting to find that the yellow separated water obtained at $\mathrm{pH}=5.7$ (Figure $7 \mathrm{~d} 1$ ) become nearly colorless (Figure 7d2) when the mixture was added with hydrochloric acid (video S3). With the decreasing of demulsification $\mathrm{pH}$ value, the GO transferred from the water to the oil phase, which can be well explained by the adjustable amphiphilicity of the GO nanosheets. ${ }^{42,43}$ The ionization of carboxyl group on the edge of GO can be tuned by 
changing the $\mathrm{pH}$ value. ${ }^{50}$ Therefore, GO can be reversibly shuttled between water and oil phase, which make it useful for recycling.

3.5 The Possible Demulsification Mechanism. The stability of the crude oil-water emulsion is attributed to repulsive force of the electrical double layer between oil droplets and the protective film consisting of molecules such as asphaltenes, resins and naphthenic acids at oil-water interface (Figure 8a1 and 8b1). ${ }^{51-54}$ Decreasing the repulsive force and/or destroying the viscoelastic film at oil/water interface are the keys to demulsify the stable emulsion. As an amphiphile, the GO nanosheets with hydrophilic edges and hydrophobic basal plane could well disperse in water phase. Once it was added into the crude oil-in-water emulsion followed with vigorous shaking (Figure $8 \mathrm{a} 2$ and $8 \mathrm{~b} 2$ ), the GO naonsheets will uniformly disperse in the water phase and reaches the oil/water interface to contact the molecules of asphaltenes and/or resins. Because of the strong interaction between GO and asphaltenes (Figure 8b3), the cortical protective film was partially destroyed in the help of collision between oil and water, producing a non-continuous protective film at the oil/water interface (Figure 8b4). The partially destroy of the protective film provides a site for the coalescence of the small oil droplets to form big ones (Figure 8b5). With the increase of coalescence and aggregation of the oil droplets (Figure 8b6), the oil phase was formed and floated up (Figure 8a3). As a result, the oil was successfully separated from water.

It is known that the GO and asphaltenes/resins have the similar chemical structure of conjugated aromatic rings, which have a huge delocalized $\pi$ systems. 
Non-covalent interactions such as the $\pi-\pi$ interaction is usually used to explain the strong adsorptions $55, \quad 56$ or self-assembling ${ }^{57,} 58$ of molecules with delocalized $\pi$ systems. Namely, one of molecules acts as $\pi$-donor and the other act as $\pi$-acceptor in stacking interactions. ${ }^{59}$ To have a better understanding on GO acting as $\pi$-donor or $\pi$-acceptor in the demulsification process, the intrinsic electronic characteristics of the graphene, GO and asphaltenes/resins are analyzed. As shown in Figure 9, the Fermi energy of graphene is 4.26-4.42 eV. ${ }^{60-62}$ After introducing the functional groups such as hydroxyl, carboxyl and alkoxyl groups, the $\pi$-conjugate systems of graphene would be polarized and the energy band would be changed as well. According to previous reports, the HOMO (the highest occupied molecular orbital) and LUMO (the lowest unoccupied molecular orbital) level of GO are $-5.2 \mathrm{eV}$ and $-1.6 \mathrm{eV}$, respectively, which were splitted comparing with that of graphene. ${ }^{63}$ As for asphaltenes, the HOMO levels range from -4.92 to $-5.41 \mathrm{eV}$ and LUMO levels range from- 1.86 to $-2.45 \mathrm{eV}$. Similarly, the HOMO levels of resins range from -4.99 to $-5.57 \mathrm{eV}$ and LUMO levels range from -1.78 to $-2.29 \mathrm{eV} .^{64}$ Taking the petroleum asphaltene inspired by UG8 Kuwait crude oil $^{65}$ as an example, the electronic properties of the petroleum asphaltene and GO model with 40 aromatic rings were calculated using density functional theory (DFT) in B3LYP/6-31G level with Gaussian 09 program package (Figure 10). The HOMO and LUMO of petroleum asphaltenes are about $-4.94 \mathrm{eV}$ and $-2.46 \mathrm{eV}$, respectively, which are in good agreement with above reported results. Obviously, the HOMO level of GO is close to that of asphaltenes (or resins), while the LUMO level of GO is slightly higher. As we 
know, the LUMO level of molecules is closely related to their adiabatic electron affinity. ${ }^{66}$ The electron affinity of molecules are more negative, the more difficult for these molecules to lose their electrons. I.e., molecules with more negative electron affinity are easier to obtain electrons from other molecules. The electron affinity of asphltenes and resins are more negative than GO, indicating that asphaltenes and resins are easier to obtain electrons from GO. In other words, asphaltenes and resins mostly act as $\pi$-acceptors, while the GO probably acts as $\pi$-donors. Based on above discussion, the polarized $\pi$ orbitals of GO (the red circle in Figure 9b) interact with the $\pi$-conjugated system of asphaltenes (or resins) (the picture in the bottom of Figure 10a) to form strong $\pi-\pi$ interactions (Figure 10c). Moreover, $\mathrm{n} \rightarrow \pi^{*}$ interaction between electron-rich functional groups (blue circle in Figure 10b) in GO and the antibonding LUMO orbital of asphaltenes (the top of Figure 10a) or resins further enhanced the strength of adsorption. ${ }^{67,68}$ Summarily, the demulsification of oil-in water emulsion driven by GO is highly related to the strong adsroption of asphatenes (resins) on GO via the $\pi-\pi / n-\pi$ interactions.

\section{Conclusions}

GO nanosheets were used as a high efficient demulsifier to break up the crude/heavy oil-in-water emulsion and/or emulsified oily wastewater. It was found that the addition of GO to crude oil-in-water emulsion could quickly destroyed the stability of the emulsion and more than $99.9 \%$ oil was separated from the emulsion within several minutes at an optimal dosage. The demulsification efficiency was affected by the properties of crude oil, the oil content of emulsion, GO dosage and the solution $\mathrm{pH}$ 
value. It was interesting to find that the distribution of GO either in oil or in water phase after demulsification was dependent on the $\mathrm{pH}$ value of the solution, which was attributed to the $\mathrm{pH}$-dependent amphiphilicity of GO. The prominent demulsification ability of GO was attributed to the strong interactions between the GO nanosheets and molecules of asphaltenes/resins which consisted a protective film at the oil-water interface. It is believed that non-covalent interactions of $\pi-\pi$ interaction and $n-\pi$ interaction account for the strong adsorption of asphaltenes/resins with the GO nanosheets. The findings in this work indicate that the GO nanosheets is a simple, high-efficient and universal demulsifier to separate the oil from the crude/heavy oil-in-water emulsions at ambient condition, which shows a good application prospect in oil industry.

\section{Author information}

*Tel.: 86-931-4968051. Fax.: 86-931-8277088. $\quad$ Email: slren@licp.cas.cn

\section{Acknowledgements}

We acknowledge the financial supports offered by National Natural Science Foundation of China (Grant No. 51374195) and the "Top Hundred Talents Program" offered by the Chinese Academy of Sciences.

\section{(S) Supporting Information}

Details of preparation of graphene oxide nanosheets and the corresponding videos in the experiment are provided in supporting information. These materials are available free of charge via the Internet at http://pubs.acs.org. 


\section{References}

(1) Kokal, S. L. Crude oil emulsions: a state-of-the-art review. SPE Prod. Facil. 2005, $20(01), 5-13$.

(2) Sjöblom, J.; Aske, N.; Auflem, I. H.; Brandal, Ø.; Erik Havre, T. E.; Sather, Ø.; Westvik, A.; Eng Johnsen, E.; Kallevik, H. Our current understanding of water-in-crude oil emulsions.: Recent characterization techniques and high pressure performance. Adv. Colloid Interface Sci. 2003, 100, 399-473.

(3) Nguyen, D.; Balsamo, V. Emulsification of heavy oil in aqueous solutions of poly (vinyl alcohol): A method for reducing apparent viscosity of production fluids. Energy Fuels 2013, 27 (4), 1736-1747.

(4) Wu, J.; Xu, Y.; Dabros, T.; Hamza, H. Effect of EO and PO positions in nonionic surfactants on surfactant properties and demulsification performance. Colloids Surf. A- Physicochemistry 2005, 252 (1), 79-85.

(5) Zhang, Z.; Xu, G.; Wang, F.; Dong, S.; Chen, Y. Demulsification by amphiphilic dendrimer copolymers. J. Colloid Interface Sci. 2005, 282 (1), 1-4.

(6) Alvarez, F.; Flores, E. A.; Castro, L. V.; Hernandez, J. G.; Lopez, A.; Vazquez, F. Dissipative particle dynamics (DPD) study of crude oil-water emulsions in the presence of a functionalized co-polymer. Energy Fuels 2011, 25, 562-567.

(7) Valencia, D.; Aburto, J.; Garcia-Cruz, I. Electronic structure and mesoscopic simulations of nonylphenol ethoxylate surfactants. a combined DFT and DPD study. Molecules 201318 (8), 9441-9450.

(8) Daniel-David, D.; Le Follotec, A.; Pezron, I.; Dalmazzone, C.; Noik, C.; Barre, L.; 
Komunjer, L. Destabilisation of water-in-crude oil emulsions by silicone copolymer demulsifiers. Oil. Gas Sci. Technol. 2008, 63 (1), 165-173.

(9) Feng, X.; Xu, Z.; Masliyah, J. Biodegradable polymer for demulsification of water-in-bitumen emulsions. Energy Fuels 2008, 23 (1), 451-456.

(10) Peng, J.; Liu, Q.; Xu, Z.; Masliyah, J. Novel magnetic demulsifier for water removal from diluted bitumen emulsion. Energy Fuels 2011, 26 (5), 2705-2710.

(11) Guzmán-Lucero, D.; Flores, P.; Rojo, T.; Martínez-Palou, R. Ionic liquids as demulsifiers of water-in-crude oil emulsions: study of the microwave effect. Energy Fuels 2010, 24 (6), 3610-3615.

(12) Silva, E. B.; Santos, D.; Alves, D. R. M.; Barbosa, M. S.; Guimarães, R. C. L.; Ferreira, B. M. S.; Guarnieri, R. A.; Franceschi, E.; Dariva, C.; Santos, A. F.; Fortuny, M. Demulsification of heavy crude oil emulsions using ionic liquids. Energy Fuels 2013, 27 (10), 6311-6315.

(13) Ali, N.; Zhang, B.; Zhang, H.; Li, W.; Zaman, W.; Tian, L.; Zhang, Q. Novel Janus magnetic micro particle synthesis and its applications as a demulsifier for breaking heavy crude oil and water emulsion. Fuel 2015, 141, 258-267.

(14) Ren, S. L.; Zhao, H.; Dang-Vu, T.; Xu, Z. H.; Masliyah, J. H. Effect of weathering on oil sands processability. Can. J. Chem. Eng. 2009, 87 (6), 879-886.

(15) Wang, Y. H.; Jia, W. H.; Ding, M. S.; Yang, H. Q.; Hu, B.; Ren, S. L. Effect of diluent addition on bitumen liberation from a glass surface. Energy Fuels 2012, 26 (2), 1019-1027.

(16) Yang, H. Q.; Wang, Y. H.; Ding, M. S.; Hu, B.; Ren, S. L. Water-assisted solvent 21 
extraction of bitumen from oil sands. Ind. Eng. Chem. Res. 2012, 51 (7), 3032-3038.

(17) Ding, M. S.; Jia, W. H.; Lv, Z. F.; Ren, S. L. Improving bitumen recovery from poor processing oil sands using microbial pre-treatment. Energy Fuels 2014, 28 (12), $7712-7720$.

(18) Ding, M. S.; Zhang, Y.; Liu, J.; Jia, W. H.; Hu, B.; Ren, S. L. Application of microbial enhanced oil recovery technology in water-based bitumen extraction from weathered oil sands. AlChE J. 2014, 60 (8), 2985-2993.

(19) Martínez-Palou, R.; Mosqueira, M. D.; Zapata-Rendón, B.; Mar-Juárez, E.; Bernal-Huicochea, C.; Clavel-López, J. D.; Aburto, J. Transportation of heavy and extra-heavy crude oil by pipeline: A review. J. Petrol. Sci. Eng. 2011, 75 (3-4), 274-282.

(20) Dai, Q.; Chung, K. H. Hot water extraction process mechanism using model oil sands. Fuel 1996, 75 (2), 220-226.

(21) Masliyah, J.; Zhou, Z. J.; Xu, Z.; Czarnecki, J.; Hamza, H. Understanding water-based bitumen extraction from Athabasca oil sands. Can. J. Chem. Eng. 2004, $82(4), 628-654$.

(22) Al-Shamrani, A.; James, A.; Xiao, H. Destabilisation of oil-water emulsions and separation by dissolved air flotation. Water Res. 2002, 36 (6), 1503-1512.

(23) Srinivasan, A.; Viraraghavan, T.; Ng, K. Coalescence/filtration of an oil-in-water emulsion in an immobilized mucor rouxii biomass bed. Sep. Sci. Technol. 2012, 47 (16), 2241-2249.

(24) Ochoa, N.; Masuelli, M.; Marchese, J. Effect of hydrophilicity on fouling of an 
emulsified oil wastewater with PVDF/PMMA membranes. J. Membr. Sci. 2003, 226 (1), 203-211.

(25) Yuliwati, E.; Ismail, A. F. Effect of additives concentration on the surface properties and performance of PVDF ultrafiltration membranes for refinery produced wastewater treatment. Desalination 2011, 273 (1), 226-234.

(26) Yuliwati, E.; Mohruni, A. S. In Membrane processing of refined palm oil wastewater using TiO2 entrapped nanoporous PVDF membrane, Appl. Mech. Mater. 2014, 548-549, 16-20.

(27) Sokker, H.; El-Sawy, N. M.; Hassan, M.; El-Anadouli, B. E. Adsorption of crude oil from aqueous solution by hydrogel of chitosan based polyacrylamide prepared by radiation induced graft polymerization. J. Hazard. Mater. 2011, 190 (1), 359-365.

(28) Moosai, R.; Dawe, R. A. Gas attachment of oil droplets for gas flotation for oily wastewater cleanup. Sep. Purif. Technol. 2003, 33 (3), 303-314.

(29) Li, G.; Wei, Y.; Wang, B.; Du, W. Research on treatment of harbor oily wastewater by coagulation-sedimentation process, Bioinformatics and Biomedical Engineering,(iCBBE) 2011 5th International Conference, 2011; IEEE: 2011, 1-4.

(30) Liu, X.; Li, J.; Zhou, B.; Cai, W. M.; Song, Y. H. Role of activated carbon adsorption in iron-carbon micro-electrolysis process for wastewater treatment. Environ. Sci. Technol. 2011, 34 (1), 128-131.

(31) Ma, S.; Wu, N.; Ma, Q.; Li, F.; Yang, J.; Li, D.; Li, J. Treatment of oily wastewater with iron-carbon internal electrolysis process enhanced by ultrasonic. $A d v$. Sci. Lett. 2013, 19 (7), 1869-1872. 
(32) Abramov, V. O.; Abramova, A. V.; Keremetin, P. P.; Mullakaev, M. S.; Vexler, G. B.; Mason, T. J. Ultrasonically improved galvanochemical technology for the remediation of industrial wastewater. Ultrason. Sonochem. 2014, 21 (2), 812-818.

(33) Tong, K.; Zhang, Y.; Liu, G.; Ye, Z.; Chu, P. K. Treatment of heavy oil wastewater by a conventional activated sludge process coupled with an immobilized biological filter. Int Biodeterior. Biodegrad. 2013, 84, 65-71.

(34) Liu, G. H.; Ye, Z.; Tong, K.; Zhang, Y. H. Biotreatment of heavy oil wastewater by combined upflow anaerobic sludge blanket and immobilized biological aerated filter in a pilot-scale test. Biochem. Eng. J. 2013, 72, 48-53.

(35) Niu, Z.; Chen, J.; Hng, H. H.; Ma, J.; Chen, X. A leavening strategy to prepare reduced graphene oxide foams. Adv. Mater. 2012, 24 (30), 4144-4150.

(36) Bi, H.; Xie, X.; Yin, K.; Zhou, Y.; Wan, S.; He, L.; Xu, F.; Banhart, F.; Sun, L.; Ruoff, R. S. Spongy graphene as a highly efficient and recyclable sorbent for oils and organic solvents. Adv. Funct. Mater. 2012, 22 (21), 4421-4425.

(37) Iqbal, M. Z.; Abdala, A. A., Oil spill cleanup using graphene. Environ. Sci. Pollut. Res. Int. 2013, 20 (5), 3271-9.

(38) Li, H.; Liu, L.; Yang, F. Covalent assembly of 3D graphene/polypyrrole foams for oil spill cleanup. J. Mater. Chem. A 2013, 1 (10), 3446.

(39) Nguyen, D. D.; Tai, N. H.; Lee, S. B.; Kuo, W. S. Superhydrophobic and superoleophilic properties of graphene-based sponges fabricated using a facile dip coating method. Energ. Environ. Sci. 2012, 5 (7), 7908-7912.

(40) Zhang, Y. L.; Chen, Q. D.; Jin, Z.; Kim, E.; Sun, H. B. Biomimetic graphene 
films and their properties. Nanoscale 2012, 4 (16), 4858-4869.

(41) Li, D.; Muller, M. B.; Gilje, S.; Kaner, R. B.; Wallace, G. G. Processable aqueous dispersions of graphene nanosheets. Nature Nanotech. 2008, 3 (2), 101-105.

(42) Cote, L. J.; Kim, J.; Tung, V. C.; Luo, J.; Kim, F.; Huang, J. Graphene oxide as surfactant sheets. Pure Appl. Chem. 2010, 83 (1), 95-110.

(43) Kim, J.; Cote, L. J.; Kim, F.; Yuan, W.; Shull, K. R.; Huang, J. Graphene oxide sheets at interfaces. J. Am. Chem. Soc. 2010, 132 (23), 8180-8186.

(44) Cote, L. J.; Kim, J.; Zhang, Z.; Sun, C.; Huang, J. Tunable assembly of graphene oxide surfactant sheets: wrinkles, overlaps and impacts on thin film properties. Soft Matter 2010, 6 (24), 6096-6101.

(45) Hummers, W. S.; Offeman, R. E. Preparation of graphitic oxide. J. Am. Chem. Soc. 1958, 80 (6), 1339-1339.

(46) Kovtyukhova, N. I.; Ollivier, P. J.; Martin, B. R.; Mallouk, T. E.; Chizhik, S. A.; Buzaneva, E. V.; Gorchinskiy, A. D. Layer-by-layer assembly of ultrathin composite films from micron-sized graphite oxide sheets and polycations. Chem. Mater. 1999, 11 (3) $771-778$.

(47) Lee, D.; De Los Santos V, L.; Seo, J.; Felix, L. L.; Bustamante D, A.; Cole, J.; Barnes, C. The structure of graphite oxide: Investigation of its surface chemical groups. J. Phys. Chem. B 2010, 114 (17), 5723-5728.

(48) Angle, C. W.; Hamza, H. A. Drop sizes during turbulent mixing of toluene-heavy oil fractions in water. AlChE J. 2006, 52 (7), 2639-2650.

(49) Liang, Y.; Wu, D.; Feng, X.; Müllen, K. Dispersion of graphene sheets in organic 
solvent supported by ionic interactions. Adv. Mater. 2009, 21 (17), 1679-1683.

(50) Shih, C. J.; Lin, S.; Sharma, R.; Strano, M. S.; Blankschtein, D. Understanding the pH-dependent behavior of graphene oxide aqueous solutions: a comparative experimental and molecular dynamics simulation study. Langmuir 2011, 28 (1), 235-241.

(51) Guo, J.; Liu, Q.; Li, M.; Wu, Z.; Christy, A. A. The effect of alkali on crude oil/water interfacial properties and the stability of crude oil emulsions. Colloids Surf. A- Physicochemistry 2006, 273 (1-3), 213-218.

(52) Poindexter, M. K.; Chuai, S.; Marble, R. A.; Marsh, S. C. Solid content dominates emulsion stability predictions. Energy Fuels 2005, 19 (4), 1346-1352.

(53) McLean, J. D.; Kilpatrick, P. K. Effects of asphaltene solvency on stability of water-in-crude-oil emulsions. J. Colloid Interface Sci. 1997, 189 (2), 242-253.

(54) Angle, C. W.; Hamza, H. A.; Dabros, T. Size distributions and stability of toluene diluted heavy oil emulsions. AIChE J. 2006, 52 (3), 1257-1266.

(55) Ersöz, A.; Denizli, A.; Şener, İ.; Atilir, A.; Diltemiz, S.; Say, R. Removal of phenolic compounds with nitrophenol-imprinted polymer based on $\pi-\pi$ and hydrogen-bonding interactions. Sep. Purif. Technol. 2004, 38 (2), 173-179.

(56) Björk, J.; Hanke, F.; Palma, C. A.; Samori, P.; Cecchini, M.; Persson, M. Adsorption of aromatic and anti-aromatic systems on graphene through $\pi-\pi$ stacking. J. Phys. Chem. Lett. 2010, 1 (23), 3407-3412.

(57) Ranganathan, D.; Haridas, V.; Gilardi, R.; Karle, I. L. Self-Assembling Aromatic-bridged serine-based cyclodepsipeptides (serinophanes): A demonstration of 
tubular structures formed through aromatic $\pi-\pi$ interactions. J. Am. Chem. Soc. 1998, 120 (42), 10793-10800.

(58) Jin, J.; Iyoda, T.; Cao, C.; Song, Y.; Jiang, L.; Li, T. J.; Zhu, D. B. Self-assembly of uniform spherical aggregates of magnetic nanoparticles through $\pi-\pi$ interactions. Angew. Chem. 2001, 113 (11), 2193-2196.

(59) Leenaerts, O.; Partoens, B.; Peeters, F. Adsorption of $\mathrm{H}_{2} \mathrm{O}, \mathrm{NH}_{3}, \mathrm{CO}, \mathrm{NO}_{2}$, and NO on graphene: A first-principles study. Phys. Rev. B 2008, 77 (12), 125416.

(60) Hohenstein, E. G.; Sherrill, C. D. Effects of heteroatoms on aromatic $\pi-\pi$ interactions: Benzene-pyridine and pyridine dimer. J. Phys. Chem. A 2009, 113 (5), $878-886$.

(61) Czerw, R.; Foley, B.; Tekleab, D.; Rubio, A.; Ajayan, P.; Carroll, D. Substrate-interface interactions between carbon nanotubes and the supporting substrate. Phys.Rev.B 2002, 66 (3), 033408.

(62) Radovic, L. R.; Bockrath, B. On the chemical nature of graphene edges: origin of stability and potential for magnetism in carbon materials. J. Am. Chem. Soc. 2005, 127 (16), 5917-5927.

(63) Tu, K. H.; Li, S. S.; Li, W. C.; Wang, D. Y.; Yang, J. R.; Chen, C. W. Solution processable nanocarbon platform for polymer solar cells. Energy Environ. Sci. 2011, 4 (9), 3521-3526.

(64) Dolomatov, M. Y.; Dezortsev, S. V.; Shutkova, S. A. Asphaltenes of oil and hydrocarbon distillates as nanoscale semiconductors. J. Mater. Sci. Eng. B 2012, 2 (2), $151-157$. 
(65) Groenzin, H.; Mullins, O. C. Molecular size and structure of asphaltenes from various sources. Energy Fuels 2000, 14 (3), 677-684.

(66) Moghal, J.; Lynch, P.; McNamara, M.; Byrne, H. J.; Chambers, G. Electrochemical characterisation of poly arylene vinylenes. J. Electroanal. Chem. 2010, 650 (1), 159-162.

(67) Hodges, J. A.; Raines, R. T. Energetics of an $n \rightarrow \pi^{*}$ interaction that impacts protein structure. Org. Lett. 2006, 8, (21), 4695-4697.

(68) Bartlett, G. J.; Choudhary, A.; Raines, R. T.; Woolfson, D. N. $n \rightarrow \pi^{*}$ interactions in proteins. Nat. Chem. Biol. 2010, 6 (8), 615-620. 
Table 1. Composition and physical properties of the Shengli heavy crude oil and Tahe crude oil.

\begin{tabular}{llc}
\hline Petroleum characterization & Value(Shengli) & Value(Tahe) \\
\hline Oil Density at $20 / 4^{\circ} \mathrm{C}\left(\mathrm{g} / \mathrm{cm}^{3}\right)$ & 0.98 & 0.86 \\
Cinematic viscosity $\left(50^{\circ} \mathrm{C}, \mathrm{mm}^{2} / \mathrm{s}\right)$ & 353.7 & 8.0 \\
Saturates $(\%)$ & 31.2 & 49.3 \\
Aromatics (\%) & 23.3 & 15.6 \\
Resins (\%) & 34.9 & 22.3 \\
Asphaltenes $(\%)$ & 9.8 & 3.4 \\
\hline
\end{tabular}



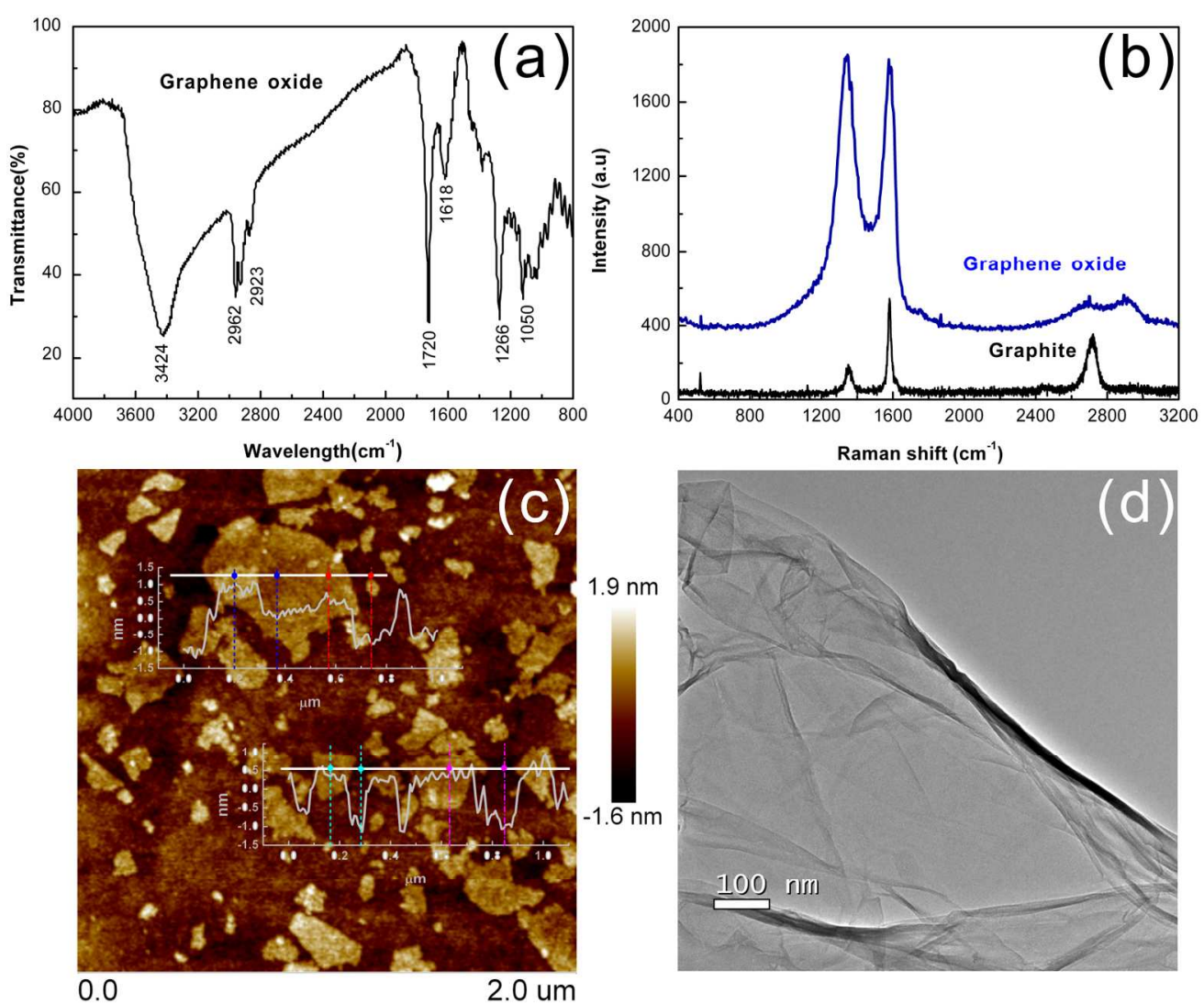

Figure 1. Various characterizations of the GO nanosheets: (a) Infrared spectrum; (b) Raman spectrum; (c) AFM images of GO on silicon substrate; and (d) TEM morphology. $150 \times 123 \mathrm{~mm}(300 \times 300 \mathrm{DPI})$ 


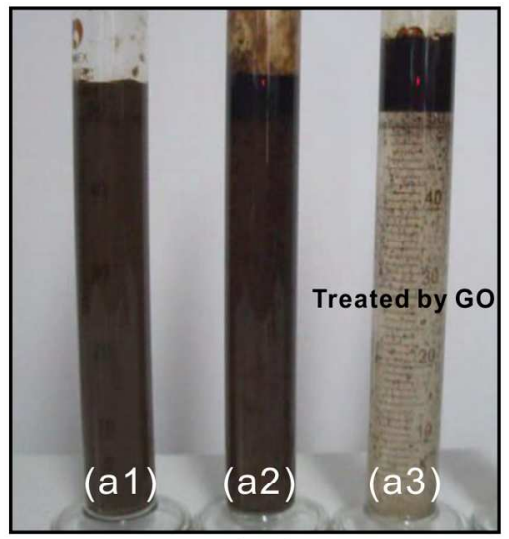

(a)

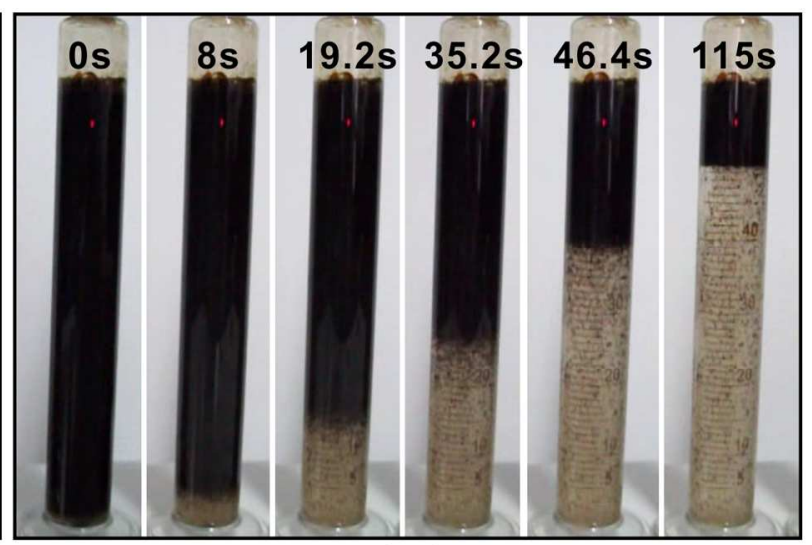

(b)

Figure 2. Visual observation on the demulsifcation : (a) bottle test of demulsification driven by GO (a3) and water (a1) or $\mathrm{HCl}$ solution (a2) as the references; (b) variation of the separation process with the increase of time. $150 \times 69 \mathrm{~mm}(300 \times 300 \mathrm{DPI})$ 


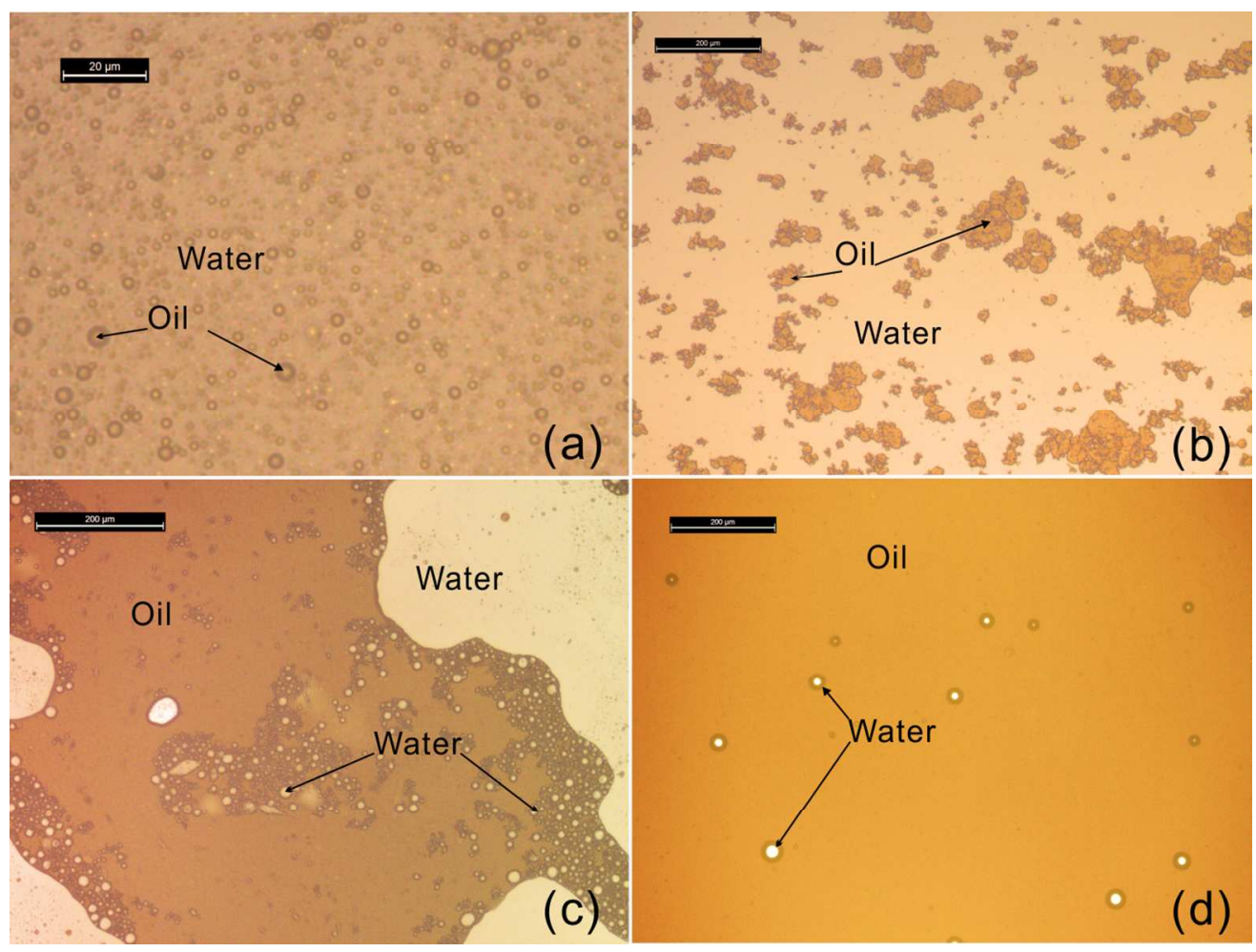

Figure 3. Micrographs of the oil-water mixture before and after demulsification: (a) The oil in water emulsion (Tahe, $50 \mathrm{~g} / \mathrm{L}$ ); (b) Coagulation of the oil droplets after addition of the $\mathrm{GO}(50 \mathrm{mg} / \mathrm{L})$ without shaking; (c) The obtained fresh oil phase after demulsification; (d) The oil phase after settle by gravity for $2 \mathrm{~h}$ at $60^{\circ} \mathrm{C}$. $119 \times 90 \mathrm{~mm}(300 \times 300 \mathrm{DPI})$ 

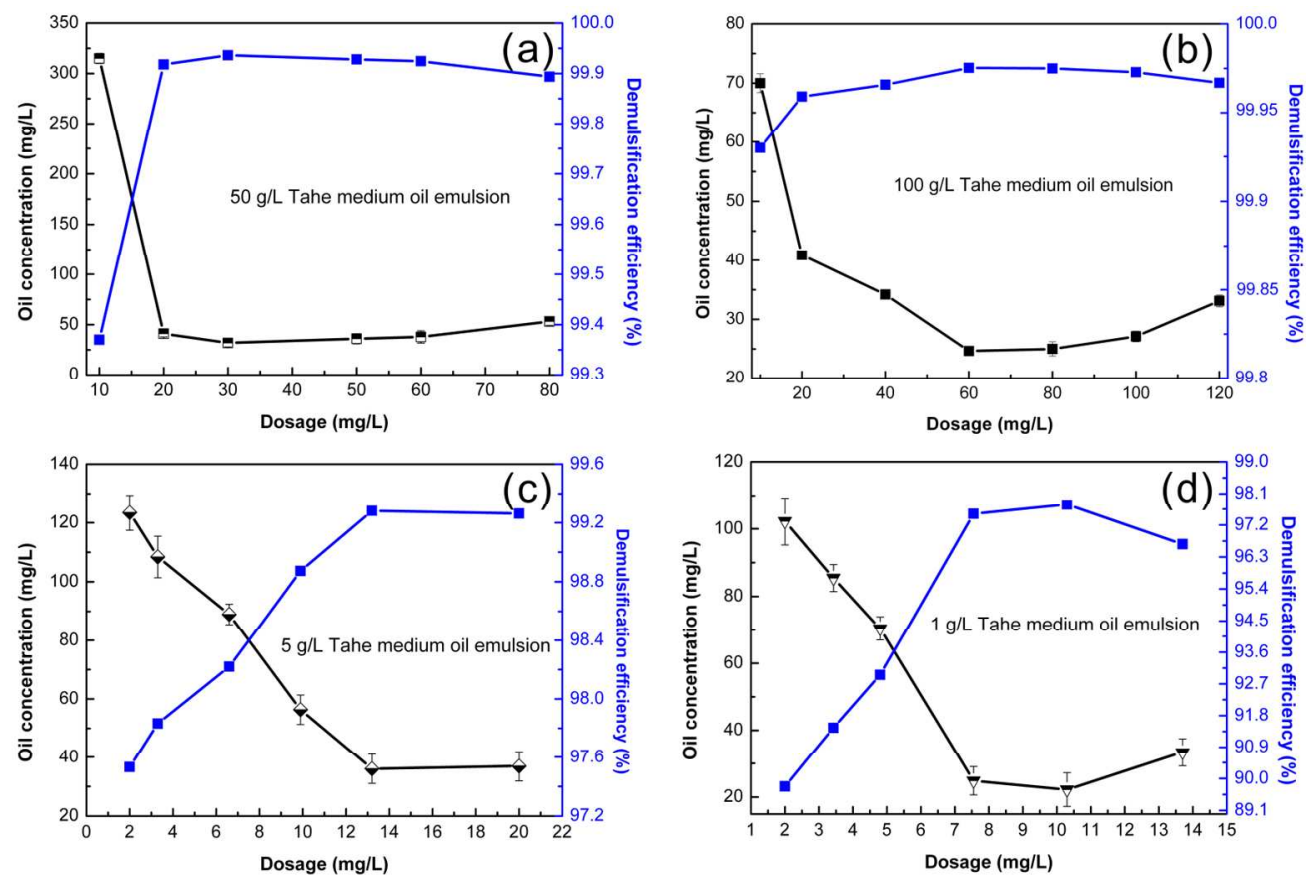

Figure 4. The residual oil content in the separated water and the corresponding demulsification efficiency as a function of GO dosages for various crude oil-in-water emulsions (Tahe). $140 \times 93 \mathrm{~mm}$ (300 x 300 DPI) 

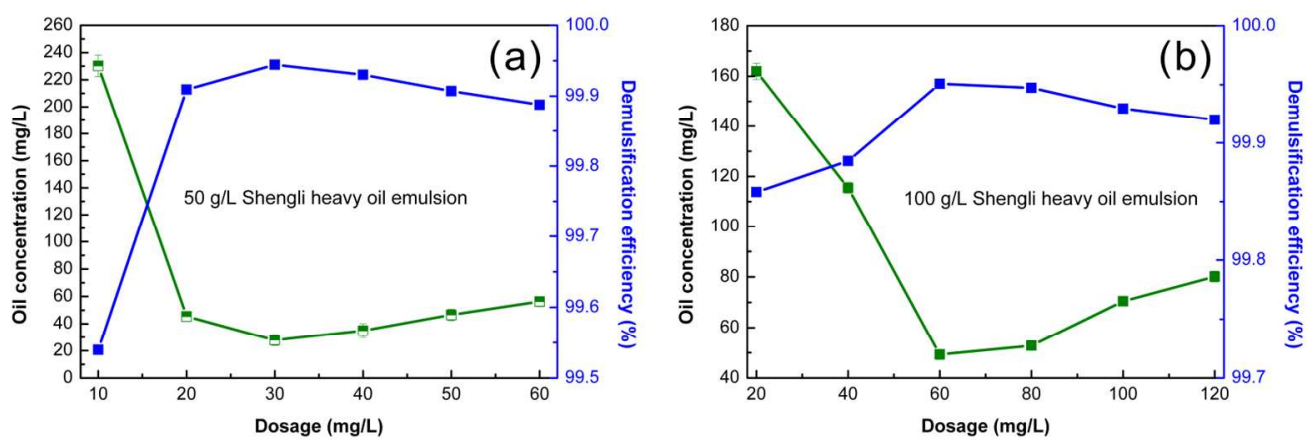

Figure 5. The residual oil content in the separated water and the corresponding demulsification efficiency as a function of GO dosages for heavy oil-in-water emulsions (Shengli). $140 \times 46 \mathrm{~mm}(300 \times 300$ DPI) 
1

2

3

4

5

6

7

8

9

10

11

12

13

14

15

16

17

18

19

20

21

22

23

24

25

26

27

28

29

30

31

32

33

34

35

36

37

38

39

40

41

42

43

44

45

46

47

48

49

50

51

52

53

54

55

56

57

58

59

60
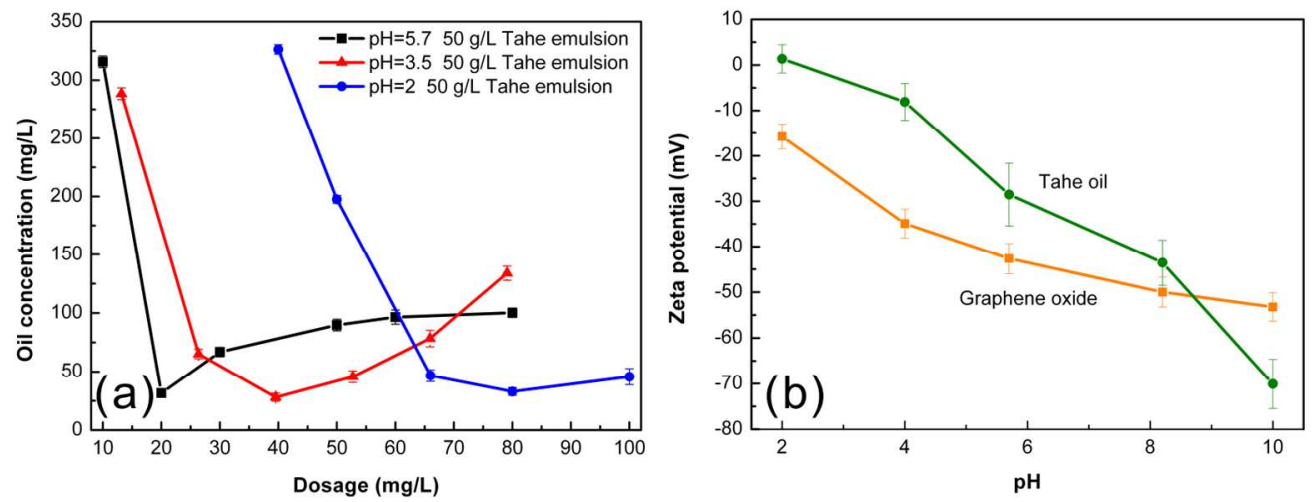

Figure 6. (a) Effect of the solution pH on the demulsification: the optimal GO dosage was significantly influenced by the emulsion pH values. (b) Zeta potential of Tahe oil droplets and graphene oxide nanosheets as a function of $\mathrm{pH}$ in $1 \mathrm{mM} \mathrm{KCl}$. $140 \times 53 \mathrm{~mm}(300 \times 300 \mathrm{DPI})$ 

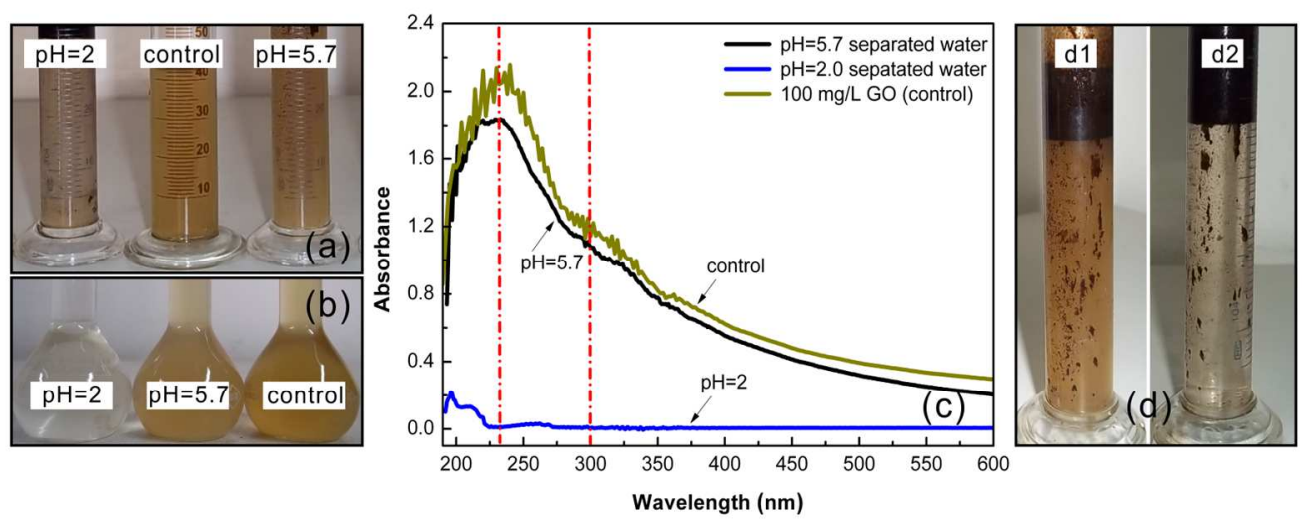

Figure 7. Effect of the GO nanosheets on the color of the separated water after demulsification: (a) the diluted GO suspension (control) and the separated water samples obtained under different pH values; (b) the corresponding water samples after extraction by toluene; (c) The UV-Vis absorption spectra of the toluene-extracted water samples; (d) variation of the water color after adjusting the solution $\mathrm{pH}$ value from 5.7 to 2 by adding hydrochloric acid. $140 \times 55 \mathrm{~mm}(300 \times 300 \mathrm{DPI})$ 


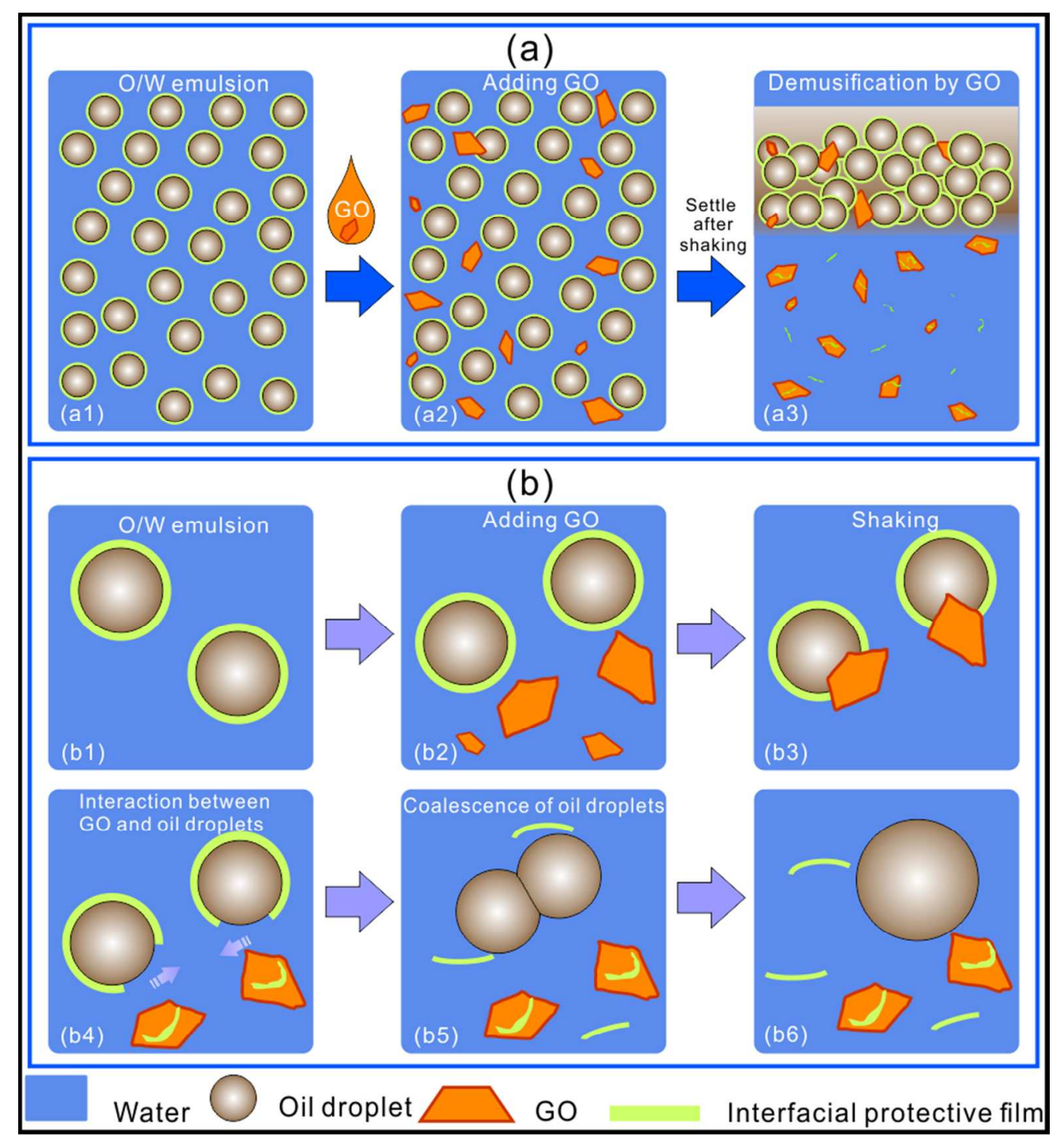

Figure 8. Schematic illustration on the demulsification processes (a) and the possible mechanism for the coagulation of the oil droplets driven by the GO nanosheets (b).

$80 \times 87 \mathrm{~mm}(300 \times 300 \mathrm{DPI})$ 


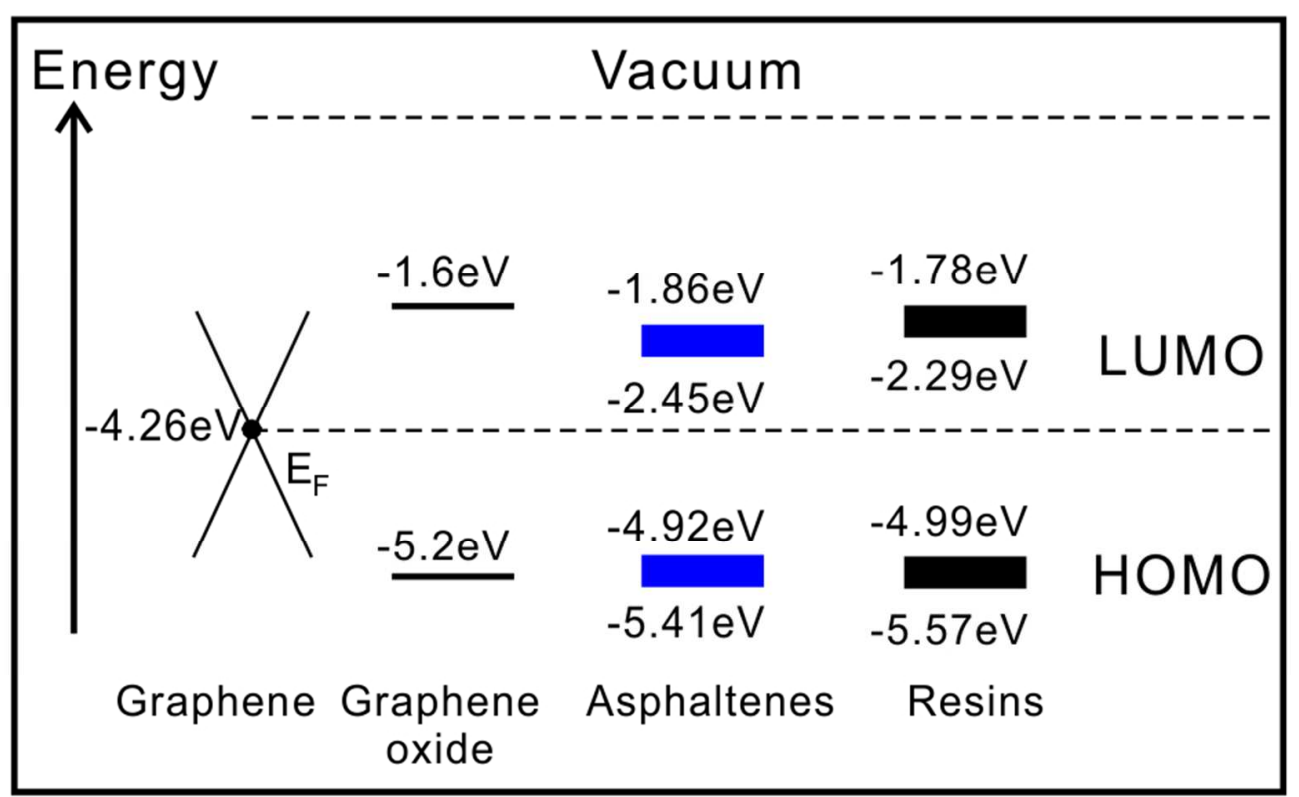

Figure 9. The relative level of the HOMO and HOMO for graphene oxide, asphaltenes, resins and the Fermi level of graphene.

$80 \times 49 \mathrm{~mm}(300 \times 300 \mathrm{DPI})$ 


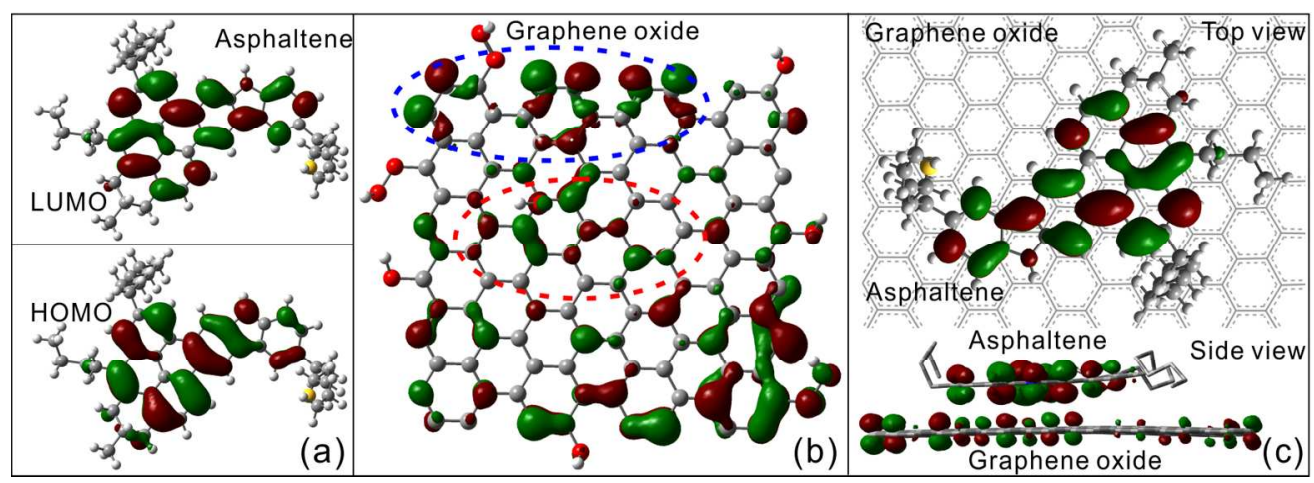

Figure 10. (a) The HOMO and LUMO for asphaltene molecules; (b) Part of the occupied orbitals of GO; and (c) The possible $п-п$ interaction between $\mathrm{GO}$ and asphaltene. $150 \times 53 \mathrm{~mm}(300 \times 300$ DPI $)$ 